\title{
Responsabilidade de Prefeitos e Vereadores
}

\section{CLENICIO DA SILVA DUARTE}

Consultor Jurídico do DASP

SUMARIO: 1. Tríplice aspecto da responsabilidade: penal, civil e político-administrativa. Apreciação, neste trabalho, apenas da primeira e última, com exclusão da segunda. 2. Responsabilidade penal, que varia em razão do agente. 3 . Natureza juridica do crime de responsabilidade incidente sôbre os Prefeitos. Distinção entre êste e os ilicitos da mesma denominação aplicáveis ao Presidente da República e Governadores de Estado. 4. Caducidade da Súmula no 301 do Supremo Tribunal Federal. A responsabilidade penal dos Prefeitos independe do afastamento do cargo, embora a condenação definitiva importe, como pena acessória, nesse afastamento. 5. Responsabilidade penal dos Vereadores. 6. Responsabilidade político-administrativa do Prefeito eleito. Inaplicabilidade dessa infração aos Prefeitos nomeados. 7. Exame dos casos de infração político-administrativa dos Prefeitos eleitos. 8. Responsabilidade político-administrailva dos Vereadores. 9. Processo e quorum de julgamento a que estão sujeitas as infrações político-administrativas. 10. Outras hipóieses de perda do mandato, independentemente de responsabilidade penal ou político-administrativa. 11. Distinção de processo re'ativamente a êsses casos e os de infração político-administrativa, 12. Conclusão.

1. O exercício de mandato eletivo de Prefeito, bem como o Verepresentante popular na Câmara Municipal, exercido pelos Vereadores, pode acarretar a responsabilidade do mandatário Soh tríplice aspecto: penal, civil e político-administrativa, cujas respectivas cominações são suscetíveis de se cumularem, pela independência que, entre si, apresentam.

Au penal, de competência processante exclusiva do Poder ciário, ou se verifica em decorrência de cometimento de 
ilícito específico denominado crime de responsabilidade ${ }^{1}$, ou de infração comum, prevista no Código Penal.

A responsabilidade civil, também de competência do Poder Judiciário, obedece a normas e processos previstos para os demais cidadãos, sem que ofereça qualquer particularidade que as afaste das regras substantivas e adjetivas aplicáveis em razão do dano civil objeto da apuração.

A responsabilidade político-administrativa, a incluir-se no âmbito do que se poderia chamar Direito Disciplinar Especial²,

1 O crime de responsabilidade praticado pelo Prefeito, eleito ou nomeado, difere, substancialmente, de ilícito de igual denominação cometido pelo Presidente da República ou por Governadores de Estado. No primeiro caso, constitui-se em autêntica responsabilidade penal, de competência da justiça comum, ao passo que, nos demais (Presidente da República e Governadores de Estado), a responsabilidade é meramente política, cuja apuração e sanção estão a cargo do Senado Federal ou das Assembléias Legislativas dos Estados, respectivamente. A condenação, na primeira hipótese, importa numa pena privativa de liberdade, além da acessória correspondente à perda do cargo e à inabilitação, pelo prazo de cinco anos, para o exercício de cargo ou função pública, eletivo ou de nomeação; nas demais, no impedimento para o exercício do cargo (impeachment), vale dizer, na cassação do respectivo mandato e pena acessória de inabilitação do condenado para o exercício de qualquer função pública durante certo prazo (Lei $n$ : 1.079, de 1950 , arts. 33 e 78), embora não exclua da responsabilidade penal, a ser apurada pelo Poder Judiciário, nos têrmos constitucionais. Mas se, no caso dos Prefeitos, se exaure a responsabilidade penal, no dos Governadores de Estado e Presidente da República, a responsabi:idade é meramente política, ainda que, concomitantemente, pela mesma infração, possa ocorrer a responsabilidade penal, o que é bem diferente, desde que o crime de responsabilidade, em si, é independente do crime comum que possa também configurar-se.

2 Como temos assinalado inúmeras vêzes (cf. nossos Estudos de Direito Administrativo, Imprensa Nacional, vol. 1, 1960, págs. 376 e segs. vol. Il, 1965, págs. 276 e segs.), o Direito Disciplinar, embora mantenha acentuada afinidade com o Direito Penal, dêle se distancia, guardando inteira autonomia relativamente àquele ramo do Direito Público, como é matéria incontroversa no estado atual da evolução jurídica, quando nem mesmo se cinge ao princípio da reserva legal (nullum crimen, nulla poena sine lege), que exige a perfeita tipicidade do ilícito em que terá de enquadrar-se a infraçăo.

Ao contrário do que ocorre com a falta puramente administrativa praticada pelos funcionários públicos, a infração político-administrativa, como seu próprio nome indica, importa em aspecto estranho, ao que se poderia chaDireito Disciplinar Comum, que é o conteúdo político da infração administrativa. Daí a denominação, que propomos, de Direito Disciplinar Espos do dado que mantém, quanto aos demais aspectos, o essencial das normas 
ocorre em razão de infrações político-administrativas, expressamente definidas em legislação específica.

Adstritos ao âmbito de incidência dêste trabalho, apreciaremos, apenas, as responsabilidades penal e administrativa, no que concerne a Prefeitos e Vereadores, com exclusão da civil, que não oferece qualquer peculiaridade relativamente ao sujeito passivo da obrigação de indenizar.

2. A responsabilidade penal varia em razão do agente do delito: se Prefeito, terá praticado crime de responsabilidade, $\mathrm{com}$ exclusão de qualquer outro ilícito penal ${ }^{3}$; se Vereador, só cometerá crime, no exercício do mandato, se a infração estiver contemplada no Código Penal, por isso que os crimes de responsabilidade não podem ter como sujeitos ativos os membros dos Legislativos municipais.

3 . Como salientado na nota 1 , supra, os crimes de responsabilidade, em relação aos Prefeitos, têm conteúdo nitidamente de infração penal, em contraposição ao que se verifica quanto aos demais Chefes de Executivo da Federação, que, como sujeitos ativos de ilícitos dessa natureza, não respondem criminalmente, mas têm identificados êsses ilícitos como infrações político-administrativas, a serem apreciadas, respectivamente, pelo Senado Federal ou pelas Assembléias Legislativas, conforme se trate de Presidente da República ou de Governador de Estado, cuja sanção é o afastamento do cargo (impeachment), o que poderá, ainda, determinar, pelo mesmo fato, responsabilidade Penal por crime comum, de competência processante do Poder Judiciário. Em outras palavras, se o crime de responsabilidade, no que tange aos Prefeitos, constitui, por si só, uma infração Penal, excludente de qualquer outra de idêntica natureza, o mesmo não acontece no que respeita ao ilícito de igual denominação praticado pelos Governadores de Estado ou Presidente da República, que só se caracteriza como infração político-administrativa.

No direito anterior ${ }^{4}$, os crimes de responsabilidade tinham a mesma conceituação, independentemente da posição do agente na escala hierárquica da Federação, conceituando-se sempre como infração político-administrativa, inconfundivel com o crime

\footnotetext{
Direito Disciplinar Comum, que não se rege por disposições substantivas riglidas, variando, tão-sòmente, no que diz com as regras adjetivas, que obedecem a formas processuais diversas.

3 Cf. Decreto-lel $n \div 201$, de 27 de fevereiro de 1967, arts. 10 e 2 .

1.079 Lei $n$ ? 3.528 , de 3 de janeiro de 1959 , combinada com a Lei $n$ ? 079, de 10 de abril de 1950.
} 
comum, tanto que não impede, pelo mesmo fato, o processo penal ${ }^{5}$.

No direito atual, os crimes de responsabilidade passaram a caracterizar-se segundo a posição do agente, ora como responsabilidade penal, com exclusão de qualquer outra da mesma natureza ${ }^{6}$, ora como responsabilidade político-administrativa, conforme praticado, respectivamente, por Prefeito ou outros Chefes de Executivo (Presidente da República e Governadores de Estado), sendo fato incontroverso que a natureza jurídica do ilícito, segundo essas duas caracterizações, é totalmente diversa.

4. Como, no direito anterior, o crime de responsabilidade, relativamente aos Prefeitos, não tinha a conceituação atual, sendo, então, mera infração político-administrativa, consoante ainda hoje se conceitua quanto ao Presidente da República e Governadores de Estado, o procedimento penal dêle decorrente ficava condicionado ao afastamento do cargo por impedimento (impeachment), ou à cessação do seu exercício por outro motivo. Êsse afastamento ou essa cessação eram um prius em relação a êsse procedimento penal, na forma de desenganada súmula do Excelso Supremo Tribunal Federal ${ }^{7}$. Vale dizer, sem 0 prévio afastamento do cargo por impeachment ou a cessação do seu exercício por outro motivo, não se poderia iniciar 0 procedimento penal respectivo, com o que, pois, não era 0 Prefeito suscetivel de responder criminalmente pelo ilícito penal que também configurasse delito de responsabilidade, se no exercício regular do cargo.

A infração que, ao mesmo tempo, configurasse crime de responsabilidade e crime comum, só seria submetida à justiça ordinária, para a competente ação penal respectiva, nos têrmos da Súmula no 301 do Supremo Tribunal Federal, se houvesse ocorrido o anterior afastamento do Prefeito por impeachment, ou se, por qualquer outro motivo, tivesse cessado o exercício do cargo, não podendo, pois, instaurar-se o procedimento criminal com o Prefeito em plena atividade de suas funções.

5 Ct. Lel $n \div 3.528$, cit. art. 2 , parágrafo único; Lei $n \div 1.079$, também mencionada, arts. 33 e 78 .

6 Cf. Decreto-lei no 201, de 1967, cit., arts. 19 e 2 ?

7 Súmula n? 301, assim redigida: "Por crime de responsabilidade, o procedimento penal contra Prefeito Múnicipal fica condicionado ao sell o procedimento penal contra Prefeito Mủnicipal fica condicionado ao por
afastamento do cargo por impeachment, ou à cessação do exercicio por
outro motivo." 
No direito vigente, perdeu o crime de responsabilidade, quanto aos Prefeitos, a natureza de verdadeira infração politico-administrativa, para conceituar-se como ilícito penal, independe dêsse afastamento, como claramente estatui, aliás, o art. 19 do Decreto-lei n? 201, de 1967, que expressamente ressalva a independência do pronunciamento da Câmara dos Vereadores para que se promova a respectiva ação penal, a cargo da justiça ordinária.

Por êsse efeito, caducou a citada Súmula no 301 do nosso Pretório Excelso, por incompatibilidade total com essa nova conceituação. É que o crime de responsabilidade, passando a conceituar-se diretamente como infração penal, de apuração privativa do Poder Judiciário, prescinde do afastamento do Prefeito, sendo ilícito totalmente independente da infração político-administrativa.

Se, no direito atual, o crime comum cometido por Presidente da República e Governador de Estado só poderá ser apurado, ou após o afastamento por crime de responsabilidade, através do impeachment, ou depois de cessado o exercício do cargo, por qualquer outro motivo, o crime de responsabilidade do Prefeito, que tem outra conceituação, como autêntico ilícito penal dispensa êsse afastamento, podendo, ou melhor, devendo instaurar-se o competente procedimento judicial tão logo se verifique a capitulação da falta em qualquer dos itens constantes do art. 19, caput, do Decreto-lei n? 201, de 1967. E se houver condenação do Prefeito, durante o exercício do cargo, terá êle, como medida acessória da condenação definitiva em pena privativa de liberdade, a perda do cargo e a inabilitação, pelo prazo de cinco anos, para o exercício de cargo ou função pública, eletivo Ou de nomeação ${ }^{8}$. E, pois, irrelevante, na apuração do crime de responsabilidade de Prefeito Municipal, estar o agente afastado ou não do exercício do cargo, sendo certo que a condenação definitiva importará nesse afastamento, se não houver ocorrido êle por qualquer outro motivo.

E possivel que, durante o processo penal por crime de responsabilidade, ocorra o afastamento do cargo, ou porque a Câmara Municipal, ao julgar concomitantemente infração polítiCo-administrativa, haja declarado o impeachment do Prefeito, Ou porque o juiz, após a denúncia, tenha decretado a prisão Preventiva ou determinado êsse afastamento. Mas, como é evidente, a cessação de exercício do cargo não é condição para

8 Decreto-lei $n \div 201$, de 1967, cit., art. 19, § 2 . 
instauração do processo penal, ao contrário do que impunha 0 direito anterior, podendo verificar-se, como esclarecido, ou independentemente ou por determinação judicial, nos autos do próprio processo por crime de responsabilidade ${ }^{2}$.

5. A responsabilidade penal dos Vereadores ocorre tão-sòmente por crimes comuns, capitulados no Código Penal, do momento em que os representantes do povo nos Legislativos não são sujeitos ativos de crime de responsabilidade. E o processo $\theta$ julgamento dos edis por crimes comuns são os mesmos dos demais cidadãos, não oferecendo, assim, nenhuma peculiaridade que se possa ressaltar, independentes que são de qualquer pronunciamento político.

6. A responsabilidade político-administrativa do Prefeito se acha indicada no art. 4\% do Decreto-lei n? 201, de 1967, sendo certo que só alcança o Chefe de Executivo local eleito, por isso que os Prefeitos nomeados, na forma da Constituição Federal ${ }^{10}$, não são sujeitos ativos de infrações dessa natureza. E a razão da distinção é simples. No primeiro caso (Prefeitos eleitos), a investidura decorre de confiança popular, expressa no sufrágio, ao passo que, no segundo (Prefeitos nomeados), o provimento no cargo resulta da confiança da autoridade nomeante (Governador de Estado) e do Presidente da República, segundo se trate, respectivamente, de Prefeito de Capital de Estado e de Municípios considerados estâncias hidrominerais, ou de Chefe de Executivo de Município declarado de interêsse da segurança nacional.

Se a investidura tem origem na escolha popular direta, a confiança dela decorrente pode ser retirada pelo próprio povo através dos seus representantes na Câmara Municipal, por meio do processo político cabível, que é a declaração de impeachment, nos têrmos e na forma previstos na legislação pertinente.

$\theta$ Idem, art. $2 \%$, no II.

10 Dispชe o $\S 1$ 10 do art. 15 da Constituição, na redação dada pela Emenda Constitucional $n$ ? 1, de 1969:

“§ 1 ? Serăo nomeados pelo Governador, com prévia aprovaçăo: a) da Assembléia Legislativa, os Prefeitos das Capitais dos Estados e dos Municípios considerados estâncias hidrominerals em lel estadual; $\boldsymbol{\theta}$

b) do Presidente da República, os Prefeitos dos Municípios declarados de interêsse da segurança nacional por lei de iniclativa do Poder Executivo." 
Se, entretanto, a investidura se origina da confiança da autoridade nomeante ou desta e do Presidente da República, só tais autoridades podem reconsiderá-la, demitindo o ocupante do Cargo; nunca pretender-se que a Câmara Municipal as substitua, visto que a origem política da investidura é totalmente diversa. Salvo nos casos de competência do Poder Judiciário ou de incidência da ação revolucionária, só pode determinar, administrativamente, a perda do cargo de confiança quem a tenha conferido. No caso de eleição, o povo, representado pela Câmara Municipal; na hipótese de nomeação, a autoridade nomeante (Governador de Estado), ou esta e o Presidente da República ${ }^{11}$.

Cometendo o Prefeito nomeado qualquer ato ou ocorrendo fato definido, em relação aos Prefeitos eleitos, como infrações político-administrativas, poderá a Câmara Municipal respectiva representar à autoridade nomeante ou a esta e ao Presidente da República, de acôrdo com a natureza do Município administrado, historiando o caso documentadamente, para que êste seja apreciado, retirando-se, ou não, a confiança anteriormente depositada. Essa faculdade, aliás, não é só da Câmara ou de cada um dos seus componentes, mas de qualquer pessoa, na forma do art. 153, § 30 , da Carta Política em vigor ${ }^{12}$.

7. As infrações político-administrativas incidentes sôbre os Prefeitos eleitos se acham capituladas, como já referido, no art. 4 !̣ do citado Decreto-lei no 201 , de 1967 , e têm como sanção a Cassação do mandato, através do impeachment. São elas:

\section{"I - impedir o funcionamento regular da Câmara."}

O princípio basilar do Estado democrático, consistente na Separação e perfeito equilíbrio dos podêres, que devem funcionar harmônicamente, embora daí se não infira que se trate de compartimentos estanques, impõe que um dêles não impeça Ou prejudique o funcionamento regular do outro, para que se exerçam as atividades públicas de acôrdo com as atribuições Próprias de cada um dêsses podêres, constitucionalmente previstas.

rìão raro, quando se fazem sentir as divergências partidárias, tão mais acentuadas no interior, os Executivos locais pro-

11

Cf. nota anterior

12

O dispositivo constitucional tem a seguinte redação:

"§ 30 . É assegurado a qualquer pessoa o direito de representação e de petição aos Podêres Públicos, em defesa de direito ou contra abusos de autoridade." 
curam sufocar os Legislativos, não liberando, sem motivo justo, os duodécimos das dotações orçamentárias aprovadas para a Câmara Municipal, de modo que esta se vê em dificuldades para manter os seus serviços mais elementares, com o que, sem sombra de dúvida, se caracteriza a infração político-administrativa prevista nesse dispositivo.

"II - impedir o exame de livros, fôlhas de pagamento e demais documentos que devam constar dos arquivos da Prefeitura, bem como a verificação de obras e serviços municipais, por comissão de investigação da Câmara ou auditoria, regularmente instituída."

O exame dos documentos a que se refere o preceito legal deverá ser feito na própria Prefeitura, não tendo cabimento pretender-se o envio de tais documentos à Câmara Municipal. Esta é que, através de comissão de inquérito regular, ou quando da àpreciação das contas do Prefeito, poderá examiná-los, marcando o Executivo dia e hora para essa diligência. O mesmo em relação a auditoria regularmente instituída.

No que concerne à verificaçăo de obras e serviços municipais, também deverá o Executivo permitir a visita a tais empreendimentos, fornecendo os esclarecimentos necessários por pessoal habilitado, a fim de que essas comissões ou auditorias tenham elementos para a verificação que desejam.

Sendo a função precípua dos parlamentos a fiscalização do Poder Executivo, tôdas as facilidades deverão ser por êste oferecidas para o cabal e eficiente desempenho dessa importantíssima missão.

"III - desatender, sem motivo justo, as convocaçōes ou os pedidos de informações da Câmara, quando feitos a tempo e em forma regular."

Para que se verifique a infração é necessário que as convocações ou os pedidos de informações sejam pertinentes à matéria administrativa ou a dados técnicos imprescindiveis, quer à fiscalização que compete à Câmara, quer à apreciação de projetos de lei que por ela estejam transitando.

"IV - retardar a publicação ou deixar de publicar as leis e atos sujeitos a essa formalidade."

A publicação a que se refere o preceito seria melhor expressada com o uso do vocábulo "divulgação", pois que, em inúmeros pequenos Municípios, não há possibilidade de publicação de atos, por inexistirem órgãos de publicidade distribuidos no Muni- 
cípio, quando, então, tais atos devem ser divulgados através de editais afixados em locais da Prefeitura, a êsse fim destinado.

"V - deixar de apresentar à Câmara, no devido tempo, e em forma regular, a proposta orçamentária."

A ocorrência do ilícito, se é de simples constatação, no que concerne ao prazo de encaminhamento da proposta orçamentária, que é claramente estipulado na Constituição do Estado ou na Lei Orgânica Municipal, oferece dificuldades no que diz com a forma regular da apresentação do projeto de lei orçamentária, nem sempre bem compreendida pelos administradores municipais. Mas é evidente que a infração só se consuma se a irregularidade é grosseira, ou decorrente de má-fé.

\section{"VI - descumprir o orçamento aprovado para o exer- cício financeiro."}

O orçamento aprovado há que ser cumprido segundo o que nêle se contém. Se advêm necessidades de sua alteração, estas devem ser efetivadas na forma estabelecida na legislação especifica.

"VII - praticar, contra expressa disposição de lei, ato de sua competência ou omitir-se na sua prática."

Essa infração político-administrativa oferece conexão com 0 crime de responsabilidade capitulado no art. 1 , $n$ ? XIV, do mesmo Decreto-lei no 201, de 1967, como se vê da redação de sua primeira parte. ${ }^{13}$

O cumprimento das leis, bem como dos mandados ou sentenças judiciais, é dever do Poder Executivo, pois que, por definição, é o encarregado da execução dos atos dos demais podêres, só se furtando a êsse dever, se o ato fôr viciado ou houver impossibilidade material de sua execução, quando se impõe esclarecer, à autoridade competente, o motivo dessa recusa ou impossibilidade.

"VIII - omitir-se ou negligenciar na defesa de bens, rendas, direitos ou interêsses do Município, sujeitos à administração da Prefeitura."

13 Dispõe o citado preceito legal:

"XIV - negar execução à lei federal, estadual ou municipal, ou deixar de cumprir ordem judicial, sem dar o motivo da recusa ou da impossibilidade, por escrito, à autoridade competente." 
Como administrador do Município, cabe ao Prefeito gerir os seus bens e rendas, bem como velar pelos seus direitos e interêsses, não se justificando qualquer ato que demonstre negligência ou omissão na gestão da coisa pública que the foi confiada, devendo administrá-la como se sua fôsse.

"IX - ausentar-se do Município, por tempo superior ao permitido em lei, ou afastar-se da Prefeitura, sem autorização da Câmara dos Vereadores."

A ausência do território do Município ou o afastamento das atividades da Prefeitura, além do período de tempo permitido em lei, há que ser autorizado pela Câmara Municipal, a exemplo do que acontece relativamente aos demais Chefes do Executivo da Federação. ${ }^{14}$

"X - proceder de modo incompativel com a dignidade e o decôro do cargo."

O Prefeito, assim como todos os demais representantes do povo, têm de pautar o seu comportamento por padrões éticos que não violem a dignidade e o decôro da representação que receberam. A alta investidura correspondente a tôda e qualquer representação popular exige um mínimo de decência que não pode ser ultrapassado, sob pena de desrespeito ao próprio povo que a conferiu.

8. A responsabilidade política-administrativa dos Vereadores pode ocorrer em qualquer dos casos enumerados no art. $7^{\circ}$ do Decreto-lei n: 201, de 1967, e que são:

a) utilizar-se do mandato para a prática de atos de corrupção ou de improbidade administrativa;

b) fixar residência fora do Município;

c) proceder de modo incompativel com a dignidade da Câmara ou faltar com o decôro na sua conduta pública.

Verifica-se, por conseguinte, que, a não ser a fixação de residência fora do Município, só se consideram infrações politico-administrativas, em relação aos Vereadores, as concernentes a atos de improbidade, de um modo geral, e falta de decôro em sua conduta pública.

9. Tanto as infrações político-administrativas dos Prefeitos eleitos como as dos Vereadores têm processo especial de apu-

14 Constituição Federal, art. 44, no III. 
ração, cujo rito obedece às normas do art. 5 \% do mesmo Decreto-lei n? 201, de 1967, se outro não fôr estabelecido pela legislação do respectivo Estado, como ali se consigna.

O julgamento é feito pela Câmara Municipal, em ambos os casos, só se impondo a sanção prevista (cassação do mandato) se o acusado fôr declarado, pelo voto de dois terços, pelo menos, dos membros da Câmara, incurso em qualquer das infrações. O resultado do julgamento é imediatamente proclamado pelo Presidente da Câmara, expedindo-se o competente decreto legislativo de cassação do mandato, se o acusado fôr - Prefeito, ou resolução da Câmara, se o acusado fôr Vereador. Se não se obtiver o quorum condenatório de dois terços, será determinado, pelo Presidente, o arquivamento do processo, comunicando-se o resultado, qualquer que seja êle, à Justiça Eleitoral. ${ }^{15}$

Sendo, como se vê, um julgamento político, cujo exame da existência ou inexistência da infração compete exclusivamente à Câmara Municipal, pode ocorrer a condenação, com a cassação do mandato respectivo, sem que o ilícito tenha ocorrido, e vice versa. E a decisão da Câmara é irrecorrivel, sendo defeso ao Judiciário apreciar-Ihe o mérito, reservando-se a êste, tão-sòmente, a competência para examinar a observância de formalidades legais e regimentais. Verificada a inobservância de qualquer formalidade essencial, poderá o Poder Judiciário decretar a nulidade do ato, mas, em hipótese alguma, substituir-se à Câmara, para perquirir da existência ou inexistência da infra̧ão.

10. Além dos casos de cassação em decorrência de crime de responsabilidade e infração político-administrativa, Prefeitos e Vereadores podem ainda perder os seus mandatos por extinção.

São casos de extinção do mandato de Prefeito: ${ }^{16}$

tos a) falecimento, renúncia por escrito, cassação dos direios políticos ou condenação por crime funcional ou eleitoral;

b) falta de posse, sem motivo justo aceito pela Câmara, dentro do prazo estabelecido em lei;

c) incidência nos impedimentos para o exercício do cargo, estabelecidos em lei, sem que haja desincompatibilização até Decreto-lei n? 201, de 1967, art. 5, nํ VI.

16 Idem, art. 6?, caput. 
a posse, e, nos casos supervenientes, no prazo que a lei ou a Câmara fixar.

Relativamente ao Vereador, extingue-se o seu mandato ${ }^{17}$ nos mesmos casos previstos para o de Prefeito e mais na hipótese de "deixar de comparecer, sem que esteja licenciado, a cinco sessões ordinárias consecutivas, ou a três sessões extraordinárias convocadas pelo Prefeito para a apreciação de matéria urgente", salvo se a convocação fôr feita durante os períodos de recesso da Câmara. ${ }^{18}$ e 18a

11. Ao contrário do que ocorre nos casos de infração político-administrativa, as hipóteses de extinção do mandato, quer de Prefeito, quer de Vereador, independem de deliberação do plenário, devendo ser declarada, de plano, pelo Presidente da Câmara Municipal, que fará constar de ata o ato ou fato extintivo. ${ }^{10}$

Também, diferentemente dos casos de infração político-administrativa, a decisão do Presidente, declarando extinto 0 mandato, pode ser objeto de apreciação pelo Poder Judiciário, que, nesta hipótese, examinará o mérito da declaração, podendo anulá-la.

A declaração de extinção do mandato, nos casos indicados no art. 89, caput, do Decreto-lei no 201, de 1967 (extinção do mandato de Vereador), de competência do Presidente da Câmara Municipal, se não-efetivada poderá ser provocada por via judicial, caso em que, "se procedente, o juiz condenará o Presidente omisso nas custas do processo e honorários de advogado que fixará de plano, importando a decisão judicial na destituição automática do cargo da Mesa e no impedimento para nova investidura durante tôda a legislatura". ${ }^{20}$

12. De um modo geral e à vol d'oiseau, são êsses os pontos essenciais da responsabilidade penal e político-administrativa

17 Idem, art. 8?, caput.

(§ 3 ? do art. 8 : do tantas vêzes citado Decreto-lei nọ 201, de 1967). mandato

18ạ Além dos casos indicados no texto, poderá ainda perder o man forma - Vereador que cometer ato de infidelidade partidária, na único do prevista no art. $35, \mathrm{n}$ ? $\mathrm{V}$, combinado com o parágrafo unico pela art. 152, ambos da Constituição Federal, na redação dada foita Emenda Constitucional $n$ ? 1, de 1969, cuja regulamentaçăo fol (Lei pelos arts. 72 e segs. da Lei Orgânica dos Partidos Políticos (Le do n? 5.682, de 21 de julho de 1971). E nessa hipótese a perda do mandato se equipara à renúncia, para efeito de convocação art. respectivo suplente (Lei Orgânica dos Partidos Políticos, cit., 72, parágrafo único).

19 Decreto-lei $n ? 201$, de 1967 , arts. 6 ? parágrafo único, e $89, \S 1$ ? 
de Prefeitos e Vereadores em decorrência do exercício de seus cargos.

Muitos dêsses ilícitos penais e político-administrativos são cometidos por desconhecimento de sua ilegalidade, quando o despreparo para o exercício de cargos dessa natureza é um fato por todos conhecido.

Os que militamos nas grandes metrópoles não podemos avaliar as imensas dificuldades da vida do interior, sem recursos e sem meios adequados, decorrentes do desenvolvimento incipiente de regiões totalmente abandonadas, perdidas na distância.

O êxodo dos mais capazes, que procuram a sua formação técnica e profissional nos centros mais desenvolvidos e que, alcançada esta, não mais retornam, deixa, apenas, nessas regiões tão carentes dêsse elemento humano qualificado, o homem simples e desprendido, que arca com o ônus da gestão da coisa pública mais por amor à sua cidade e aos seus convizinhos, num esfôrço que o nobilita, do que pela atração do mando, pela vaidade do poder.

Em nossas andanças municipalistas por êste Brasil afora, nos contatos mais diversos com o homem bom e simples do interior, temos encontrado uma vontade ingente de aprender, uma ânsia de adquirir conhecimentos com que possa o administrador dar aos problemas públicos que equaciona as soluções mais acertadas, dentro das peculiaridades regionais, sem desprêzo dos princípios que informam o Direito e a Ética. Se, vez por outra, há deslize de conduta, é um caso esporádico, que não faz escola. 


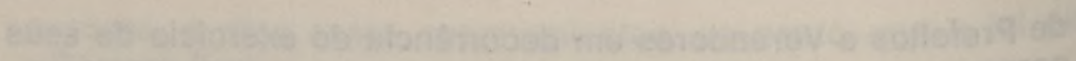
2000750

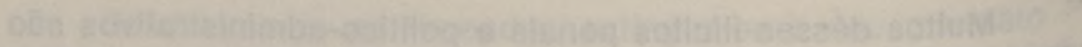

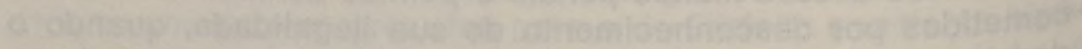

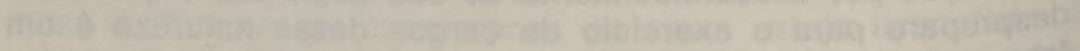

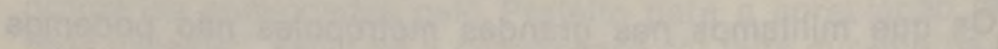

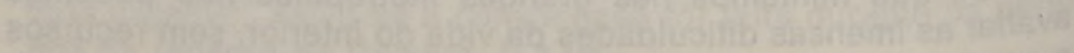

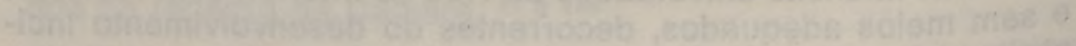

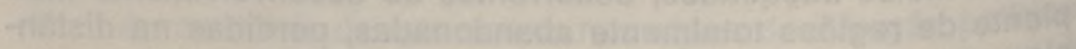

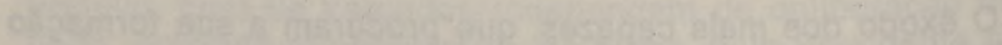

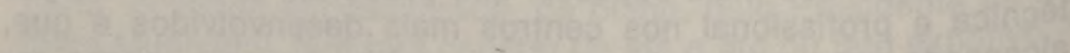

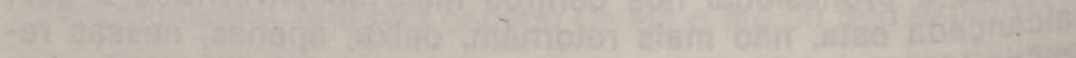

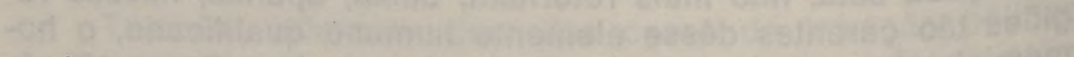

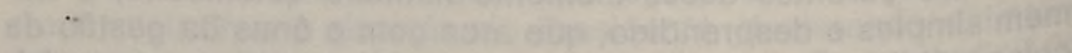

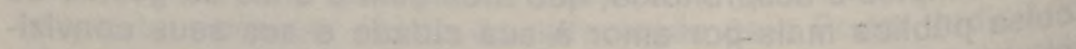

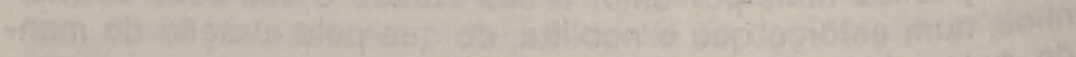

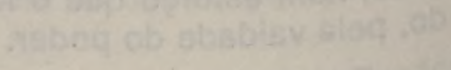

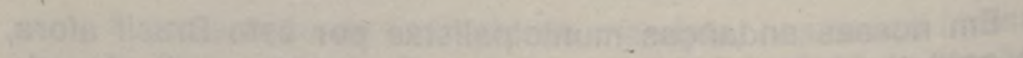

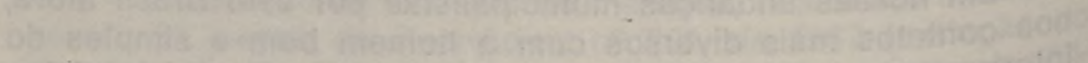
16:-

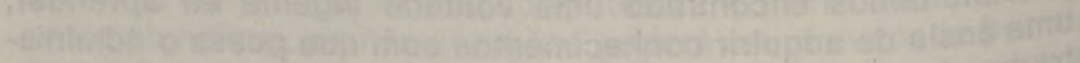

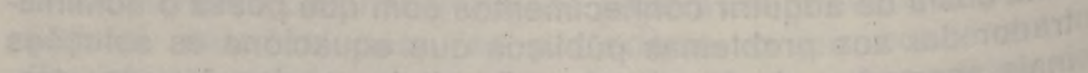

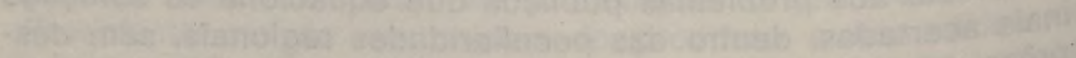

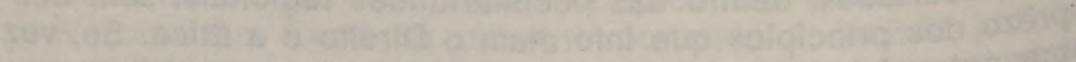

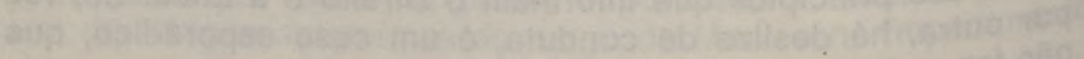

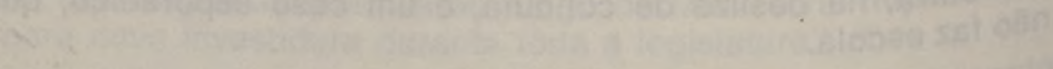

